\title{
Clinical and prognostic value of hTERT mRNA expression in patients with non-small-cell lung cancer
}

\author{
Marzena Zalewska-Ziob1, Katarzyna Dobija-Kubica², Krzysztof Biernacki', Brygida Adamek³, \\ Janusz Kasperczyk ${ }^{4}$, Krzysztof Bruliński ${ }^{5}$ and Zofia Ostrowska ${ }^{1}$
}

'Chair and Department of Medical and Molecular Biology, School of Medicine with the Division of Dentistry in Zabrze, Medical University of Silesia, Katowice, Poland; ${ }^{2}$ John Paul II Hospital of Oncology, General Surgery Ward, Bielsko Biała, Poland; ${ }^{3}$ Department of Basic Medical Sciences, School of Public Health in Bytom, Medical University of Silesia, Katowice, Poland; ${ }^{4}$ Chair and Department of Environmental Medicine and Epidemiology, School of Medicine with the Division of Dentistry in Zabrze, Medical University of Silesia, Katowice, Poland; ${ }^{5}$ Specialist Hospital of Lung Diseases and Tuberculosis, Thoracic Surgery Ward, Bystra Sląska, Poland

Telomerase, undetectable in normal somatic cells, plays a critical role in carcinogenesis of the majority of human tumors including lung carcinoma. The aim of our study was to determine human telomerase reverse transcriptase ( $h T E R T)$ mRNA expression in patients with nonsmall cell lung cancer (NSCLC) in order to estimate its usefulness as diagnostic and/or prognostic factor. hTERT expression was analyzed in a group of 12 females and 28 males with NSCLC using Quantitative Real-Time Polymerase Chain Reaction (QRT-PCR method) in cancerous and non-cancerous lung tissues. Results were analyzed according to clinical data and one-, two-, and five-year survival rates. hTERT expression in the cancerous tissue was significantly higher than in the lung parenchyma free from neoplasm infiltration $(p<0.05)$. There was no significant association between hTERT expression in the tumor tissue and age, gender, grading or clinical stage. A significant difference in $h T E R T$ expression between two types of histopathological patterns (adenocarcinoma and squamous cell carcinoma) was detected $(p=0.01)$. No association between $h T E R T$ expression in NSCLC specimens and survival rates was found. hTERT mRNA detection by QRT-PCR in tumor and corresponding cancer-free tissues can be used as a diagnostic marker in patients with NSCLC, but seems not to be a prognostic factor.

Key words: non-small-cell lung cancer, telomerase, hTERT expression, survival rate, prognosis

Received: 03 June, 2017; revised: 27 July, 2017; accepted: 10 September, 2017; available on-line: 15 November, 2017

e-mail: m.zalewska.sne@gmail.com

Abbreviations: hTERT, human telomerase reverse transcriptase GAPDH, glyceraldehyde 3-phosphate dehydrogenase; NSCLC, non-small-cell lung cancer; SCC, squamous cell carcinoma; PTNM, pathological tumor-node-metastasis staging; G, grading; CDNA, complementary deoxyribonucleic acid; RNA, ribonucleic acid; RT, reverse transcription; QRT-PCR, quantitative real time-polymerase chain reaction

\section{INTRODUCTION}

Lung cancer is one of the most important cause of cancer-related mortality worldwide, and the most frequent cause of deaths in Poland (Parkin et al., 2005; Radziszewska et al., 2015). The WHO has categorized lung cancers into non-small cell lung cancer (NSCLC) and small cell lung cancer (SCLC) based on cancer biology, therapy responsiveness and prognosis (Goldstraw et al., 2007). NSCLC, diagnosed as three common types: adenocarcinoma, squamous cell carcinoma and large cell carcinoma, accounts for more than $85 \%$ of all lung cancer cases (Ettinger et al., 2010). For these lung cancer types surgery is the only therapeutic option nowadays. Due to the low effectiveness of the therapy and high mortality of patients with NSCLC, there is still a need to discover markers useful either in diagnostics and qualification for surgical treatment or in prognostics.

Telomeres are DNA-protein structures located at the 3 ' ends of DNA strands, composed of repeated guanine-rich sequences 5'-T'TAGGG-3' and stabilized by an associated protein (shelterin complex). Their role is to protect chromosome ends from degradation by exonucleases and prevent non-homologous end joining; therefore, they are essential for the maintenance of genomic integrity (Armanios et al., 2012; Mocellin et al., 2013; Palm et al., 2008). The telomeres' length is set in the germline but decreases in somatic cells, primarily as a result of the inability of DNA polymerase to complete replication of the lagging strand ("end replication problem"). Telomerase is a ribonucleoprotein polymerase that maintains telomere ends by catalyzing the addition of TTAGGG repeats. Human telomerase consists of two major components (protein and RNA): human telomerase reverse transcriptase catalytic subunit (hTERT) and a functional telomerase RNA (hTR, hTERC) (Palm et al., 2008; Shay et al., 2000; Shay et al., 2005; Weinrich et al., 1997). Telomerase uses its RNA component (which contains an 11-bp sequence complementary to the telomeric single stranded overhang) as a template for synthesizing telomeric cDNA (TTAGGG) directly onto the ends of chromosomes. Telomerase expression plays a role in cellular senescence, as it is normally repressed in postnatal somatic cells, resulting in progressive shortening of telomeres. Telomere shortening to a critical length results in the loss of telomere protection, which leads to chromosome instability, stops cell division and replicative senescence may be initiated (Shay et al., 2005). Some cells, however, exhibit unlimited capacity for proliferation through the telomerase complex activity (Palm et al., 2008; Weinrich et al., 1997). In the large majority of cancer cells, telomere length is maintained by telomerase. Thus, telomere length and telomerase activity are crucial for cancer initiation and the survival of tumors (Jafri et al., 2016). Several studies on the relationship between telomerase activity and prognosis in lung cancer have been reported (Hara et al., 2001; Marchetti et al., 1999). The expression of $b T E R T$ was frequently detected in lung cancer as was telomerase activity (Albanell et al, 1997; van den Berg et al., 2010; Wang et al., 2002) but the results of these studies are ambiguous. 
The aim of this study was to determine the clinical significance of human telomerase reverse transcriptase (bTERT) mRNA expression in patients with NSCLC and to evaluate its usefulness as a diagnostic parameter and a prognostic factor in this group of patients.

\section{MATERIALS AND METHODS}

Patients and samples. A group of 40 patients diagnosed with NSCLC and treated in the Thoracic Surgery Ward of the Specialist Hospital of Lung Diseases and Tuberculosis in Bystra Slaska in 2009-2010 were enrolled into the study. The cohort of patients included 12 females $(30 \%)$ and 28 males $(70 \%)$, aged 47 to 75

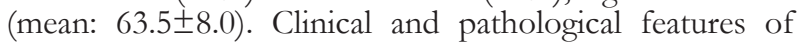
the patients are presented in Table 1.

During surgery, specimens of the tumor tissue and the lung parenchyma free from neoplastic infiltration (taken no less than $5 \mathrm{~cm}$ from the visible edge of the tumor) were obtained. Each sample was immediately snap-frozen in a separate tube with liquid nitrogen and stored at $-80^{\circ} \mathrm{C}$ until it was used for quantitative real-time PCR (QRT-PCR). After that the samples were transported on dry ice for further examination at the Molecular Research Laboratory of the Department of Medical and Molecular Biology in Zabrze.

The advancement of NSCLC was determined with the clinical TNM scale and histopathological examination of tumor cell differentiation grading $(G)$ made independently by two pathomorphologists.

RNA extraction, reverse transcription and QRTPCR for hTERT and a housekeeping gene GAPDH. Isolation of the total RNA from about $80 \mathrm{mg}$ of frozen tissue samples was performed with the RNeasy ${ }^{\circledR}$ Midi Kit (Qiagen, Germany). Apart from the standard procedure, DNase I (Qiagen, Germany) was used to remove trace amounts of genomic DNA. RNA was quantified by measuring the absorbance at 260 and $280 \mathrm{~nm}$ and the integrity was assessed by electrophoresis in a $1.2 \%$ agarose gel stained with ethidium bromide. RNA isolates were used to synthesize cDNA in the RT reaction. $200 \mathrm{ng}$ of total RNA was transcribed into cDNA in a total volume of $20 \mu \mathrm{l}$ by the High-Capacity cDNA Archive Kit (Applied Biosystems, USA) following the manufacturer's instruction. Obtained cDNA was used to determine bTERT gene expression using a quantitative real-time PCR assay (TaqMan ${ }^{\circledR}$ system). TaqMan ${ }^{\circledR}$ primers and a probe for hTERT were bought as ready to use TaqMan $^{\circledR}$ Gene Expression Assays (Hs00972656_m1) and for the housekeeping gene GAPDH Endogenous Control (Hs02758991_g1) (Applied Biosystems, USA). Q-PCR was conducted for both genes in a volume of 20 $\mu \mathrm{l}$ on the ABI PRISM 7300 Real Time PCR Detection System (Applied Biosystems, USA). Each time, a Q-PCR mix was prepared on ice with $10 \mu$ l of Applied Biosystems Universal PCR Master Mix, $1 \mu$ of "primers and probe mix", and $8 \mu \mathrm{l}$ of $\mathrm{H}_{2} \mathrm{O}$ (Qiagen, Germany). To each well of a 96-well plate, $19 \mu \mathrm{l}$ of Q-PCR mix and $1 \mu \mathrm{l}$ of cDNA were added. All PCRs were conducted in triplicates. A negative control was included for all amplification reactions. bTERT and GAPDH genes were amplified starting with the incubation step at $50^{\circ} \mathrm{C}$ for 2 minutes, followed by the first denaturation step at $95^{\circ} \mathrm{C}$ for 10 minutes, and continuing with 40 cycles of $95^{\circ} \mathrm{C}$ for 15 seconds, $60^{\circ} \mathrm{C}$ for 1 minute. Gene expression was considered negligible when the Ct (threshold cycle) value was greater than 40 . In view of the heterogeneity of the investigated tissue and the lack of ability to use a commercially available standard, to determine bTERT expression the $\Delta \mathrm{C}_{\mathrm{T}}$ method was applied (Livak et al., 2001).

Thanks to the kindness of the Document Personalization Centre of the Ministry of Internal Affairs and Administration in Warsaw, Poland, we got access to information about the patients' dates of death, which were needed to calculate survival time. Thus, 1-, 2-, and 5-year survival rates were calculated and then correlated with bTERT expression in cancerous and non-cancerous tissues.

Statistical analyses. Statistical analyses were performed to examine the correlation between bTERT mRNA expression and the clinical parameters of NSCLC patients. Qualitative variables are presented in absolute terms (number of patients showing the presence of a variable) and as a percentage of the entire analyzed study group, while qualitative variables were expressed as a mean and a standard deviation (S.D.). The obtained data were statistically analyzed based on the Student's $t$-test or Mann-Whitney U-test $(p<0.05$ was considered statistically significant). Pearson, Kendall and Spearman rank correlation coefficients were used to detect monotonic and non-monotonic correlations in this study. Survival curves were calculated by the Kaplan-Meier method and were compared using Gehan's generalized Wilcoxon test. Statistical analyses were performed using the STATISTICA 12.0 software (StatSoft. Inc., Tulsa, OK, USA). The study protocol was approved by the Ethical Committee of the Medical University of Silesia in Katowice, Poland (KNW/0022/

Table 1. The clinical and pathological features of 40 NSCLC patients.

\begin{tabular}{ll}
\hline Variable & Number of patients (\%) \\
\hline Total number & $40(100)$ \\
\hline Age & \\
$\leq 65$ & $21(52.5)$ \\
$>65$ & $19(47.5)$ \\
\hline Histology & $29(72.5)$ \\
Squamous cell carcinoma & $11(27.5)$ \\
Adenocarcinoma & $0(0.0)$ \\
Large cell carcinoma & \\
\hdashline Differentiation grade & $0(0.0)$ \\
G1 & $17(42.5)$ \\
G2 & $23(57.5)$ \\
G3 & \\
\hline T factor & $9(22.5)$ \\
T1 & $24(60.0)$ \\
T2 & $6(15.0)$ \\
T3 & $1(2.5)$ \\
T4 & \\
\hdashline N factor & $20(50.0)$ \\
N0 & $14(35.0)$ \\
N1 & $6(15.0)$ \\
N2 & $13(32.5)$ \\
\hdashline Clinical stage & $17(42.5)$ \\
I & $8(20.0)$ \\
II & $2(5.0)$ \\
III Undefined & $28(70.0)$ \\
Survival rates & $26(65.0)$ \\
one-year & $25(62.5)$ \\
two-year & \\
five-year & \\
\hline
\end{tabular}

The abbreviations: G, histopathological cancer grading (G1, well differentiated; $\mathrm{G} 2$, moderately differentiated; $\mathrm{G} 3$, poorly differentiated); $\mathrm{T}$, tumor size; N, metastatic lymph nodes. 
KB1/119/I/09). Informed consents were obtained for all study participants.

\section{RESULTS}

The study group characteristics are shown in Table 1. The expression of BTERT was detected in 39 out of 40 $(97.5 \%)$ of surgery excised NSCLC tissue while in visually normal lung tissue it was observed in 24 out of 32 specimens $(75 \%)$. Moreover, the average bTERT expression (average $\Delta \mathrm{C}_{\mathrm{T}}$ ) in neoplastic tissue was 0.000665 , and it was significantly higher than the average bTERT expression in the parenchyma of the lung without tumor infiltration (0.000189), $\left(p=5.24 \times 10^{-4}\right)$. A significant difference in bTERT expression between two types of histopathological patterns (adenocarcinoma and SCC) was also detected $(\mathrm{p}=0.01)$. On the other hand, no significant differences in bTERT expression in tumor tissues between gender, age, grading $(\mathrm{G})$, clinical stage, size of the tumor ( $\mathrm{T}$ ) and degree of involvement of regional lymph nodes (N) were observed (Table 2). Significant differences in bTERT expression in non-cancerous tissues between gender, age, histological type, grading, clinical stage, $\mathrm{T}$ and $\mathrm{N}$ parameters were not observed (Table 3). A correlation between bTERT expression in the tumor and $b T E R T$ in non-cancerous tissues was not found.

During the five-year observation period, one-year, two-year, and five-year survival rates of the 40 patients treated with surgery were evaluated. Within one year after surgery 12 patients $(30 \%)$, within two years 14 patients $(35 \%)$, and within five years 15 patients $(37.5 \%)$

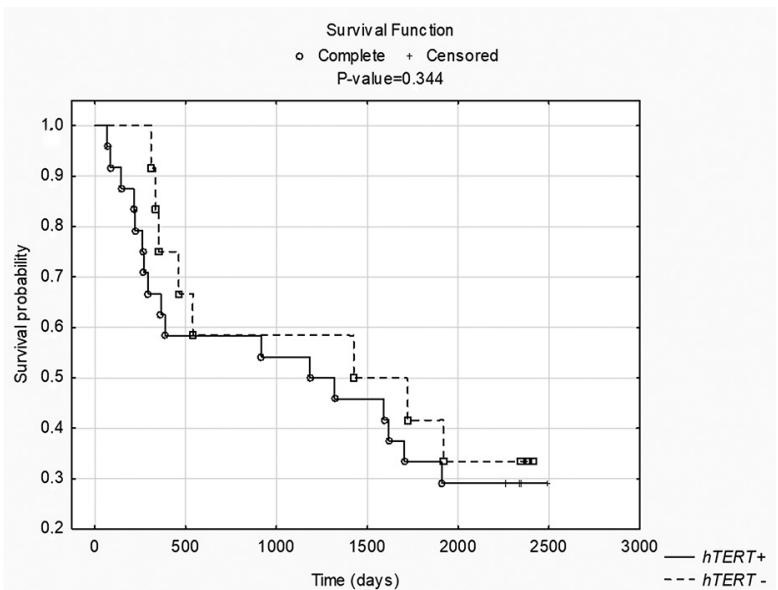

Figure 1. Survival analysis of patients with NSCLC based on the classification of $h T E R T$-positive and -negative mRNA expression in non-cancerous tissues.

The figure shows overall survival curves analyzed using the Kaplan-Meier method.

died due to the progression of the disease. Individual survival rates are presented in Table 1. Comparing bTERT expression in tumor tissues of still living and deceased patients we did not find important differences one year, two, and five years after surgery (Table 2).

Subsequently we analyzed the relationship between bTERT expression in non-cancerous tissues and length of survival. There were no significant differences in

Table 2. hTERT mRNA expression in NSCLC tumor specimens depending on various clinical and pathological factors.

\begin{tabular}{|c|c|c|c|c|c|}
\hline Clinical and pathological fac & & $\mathrm{N}$ & $\%$ & Average hTERT expression $\left(\Delta C_{t}\right)$ & $p$ \\
\hline \multirow{2}{*}{ Gender } & $\mathrm{F}$ & 12 & 30.00 & 0.000692 & \multirow{2}{*}{0.88} \\
\hline & M & 28 & 70.00 & 0.000654 & \\
\hline \multirow{2}{*}{ Age } & $\leq 65$ & 21 & 52.50 & 0.000857 & \multirow{2}{*}{0.08} \\
\hline & $>65$ & 19 & 47.50 & 0.000454 & \\
\hline \multirow{2}{*}{ Type of histological pattern } & squamous cell carcinoma & 29 & 72.50 & 0.000494 & \multirow{2}{*}{0.01} \\
\hline & adenocarcinoma & 11 & 27.50 & 0.001116 & \\
\hline \multirow{2}{*}{ Grading } & $\mathrm{G} 2$ & 17 & 42.50 & 0.000653 & \multirow{2}{*}{0.93} \\
\hline & G3 & 23 & 57.50 & 0.000674 & \\
\hline \multirow{2}{*}{ Clinical stage } & 1 & 13 & 32.50 & 0.000473 & \multirow{2}{*}{0.30} \\
\hline & II-III & 25 & 62.50 & 0.000729 & \\
\hline \multirow{2}{*}{ T: Primary tumor } & $\mathrm{T} 1$ & 9 & 22.50 & 0.00036 & \multirow{2}{*}{0.14} \\
\hline & $\mathrm{T} 2-\mathrm{T} 3$ & 30 & 75.00 & 0.00077 & \\
\hline \multirow{2}{*}{$\mathrm{N}$ : Lymph nodes } & No & 20 & 50.00 & 0.000613 & \multirow{2}{*}{0.66} \\
\hline & $\mathrm{N} 1-\mathrm{N} 2$ & 20 & 50.00 & 0.000717 & \\
\hline \multirow{2}{*}{ One-year survival } & yes & 28 & 70.00 & 0.000683 & \multirow{2}{*}{0.82} \\
\hline & no & 12 & 30.00 & 0.000624 & \\
\hline \multirow{2}{*}{ Two-year survival } & yes & 26 & 65.00 & 0.000642 & \multirow{2}{*}{0.78} \\
\hline & no & 14 & 35.00 & 0.000709 & \\
\hline \multirow{2}{*}{ Five-year survival } & yes & 25 & 62.50 & 0.000644 & \multirow{2}{*}{0.81} \\
\hline & no & 15 & 37.50 & 0.000701 & \\
\hline
\end{tabular}


Table 3. hTERT mRNA expression in non-cancerous lung specimens depending on various clinical and pathological factors.

\begin{tabular}{|c|c|c|c|c|c|}
\hline \multicolumn{2}{|c|}{ Clinical and pathological factors } & \multirow{2}{*}{$\begin{array}{l}\mathrm{N} \\
9\end{array}$} & \multirow{2}{*}{$\begin{array}{l}\% \\
28.12\end{array}$} & \multirow{2}{*}{$\begin{array}{c}\text { Average } h T E R T \text { expression }\left(\Delta \mathrm{C}_{\mathrm{t}}\right) \\
0.000174\end{array}$} & \multirow{3}{*}{$\begin{array}{l}p \\
0.73\end{array}$} \\
\hline \multirow{2}{*}{ Gender } & $\mathrm{F}$ & & & & \\
\hline & M & 23 & 71.88 & 0.000195 & \\
\hline \multirow{2}{*}{ Age } & $\leq 65$ & 15 & 46.88 & 0.000189 & \multirow{2}{*}{1.00} \\
\hline & $>65$ & 17 & 53.12 & 0.000189 & \\
\hline \multirow{2}{*}{ Type of histological pattern } & squamous cell carcinoma & 22 & 68.75 & 0.00017 & \multirow{2}{*}{0.29} \\
\hline & adenocarcinoma & 10 & 31.25 & 0.000232 & \\
\hline \multirow{2}{*}{ Grading } & $\mathrm{G} 2$ & 11 & 34.38 & 0.000162 & \multirow{2}{*}{0.52} \\
\hline & G3 & 20 & 62.50 & 0.0002 & \\
\hline \multirow{2}{*}{ Clinical stage } & 1 & 8 & 25.00 & 0.000222 & \multirow{2}{*}{0.45} \\
\hline & II-III & 23 & 71.88 & 0.000174 & \\
\hline \multirow{2}{*}{$\mathrm{T}$ : Primary tumor } & $\mathrm{T} 1$ & 6 & 19.35 & 0.000232 & \multirow{2}{*}{0.47} \\
\hline & T2-T3 & 25 & 80.65 & 0.00018 & \\
\hline \multirow{2}{*}{$\mathrm{N}$ : Lymph nodes } & No & 13 & 40.62 & 0.000226 & \multirow{2}{*}{0.26} \\
\hline & $\mathrm{N} 1-\mathrm{N} 2$ & 19 & 59.38 & 0.000164 & \\
\hline \multirow{2}{*}{ One-year survival } & yes & 22 & 68.75 & 0.000177 & \multirow{2}{*}{0.50} \\
\hline & no & 10 & 31.25 & 0.000217 & \\
\hline \multirow{2}{*}{ Two-year survival } & yes & 17 & 53.13 & 0.000148 & \multirow{2}{*}{0.10} \\
\hline & no & 15 & 46.87 & 0.000236 & \\
\hline \multirow{2}{*}{ Five-year survival } & yes & 16 & 50.00 & 0.000154 & \multirow{2}{*}{0.19} \\
\hline & no & 16 & 50.00 & 0.000225 & \\
\hline
\end{tabular}

bTERT expression between living and deceased patients one, two, and five years after surgical treatment (Table 3). The overall survival curves analyzed using the Kaplan-Meier method are shown in Fig. 1. During the 5 -year observation period, the probability of survival between the group of patients showing bTERT expression in non-cancerous tissues and the group not exhibiting such expression was not significantly different $(p=0.33)$.

\section{DISCUSSION}

Currently the best predictor of outcome is the p'NM system and it has been shown that benefits from surgical treatment are determined by lower staging at the moment of diagnosis (van den Berg et al., 2010). Unfortunately, the overwhelming part of Polish patients are diagnosed at advanced stages of lung cancer. Thus, they cannot be offered a radical surgical treatment. Recent data show that only about $16 \%$ of patients are qualified to surgical procedures. Consequently, the five-year survival rates in our country are highly unsatisfactory (Radziszewska et al., 2015).

Among more than 100 proposed cancer markers, telomerase is detected in almost all kinds of cancer tissues. Telomerase activity has been found in approximately 85$90 \%$ of the most common cancers such as breast, prostate, lung, liver, pancreatic, and colon cancers (Hiyama et al., 2001; Kim 1997; Shay et al., 1997). As telomerase activity appears in most tumor cells at the preneoplastic or in situ stage, it may be useful for early detection of cancer, especially in cytology samples. In other instances, in which the level of telomerase activity is not high but increases with cancer progression, telomerase activity levels in tumor tissues may be prognostic indicators of the patient's outcome (Hiyama et al., 2002; Shay et al., 1997).

In our previous study (Dobija-Kubica et al., 2016) we showed even though the telomerase activity was significantly higher in NSCLC tissue specimen than in the lung parenchyma free from tumor infiltration, there was a lack of significant differences according to other clinical parameters. This suggests that telomerase activity is connected only with the tumor cell proliferation. On the other hand, the variation in telomerase activity in cancer tissues might be associated with different levels of telomerase expression in each tumor cell. The difference may result from the absolute number of tumor cells that show telomerase activity (Hiyama et al., 2001). Therefore, the present study assessed the utility of hTERT expression as a diagnostic and/or prognostic factor.

The presence of $b T E R T$ mRNA is essential for enzymatic activity so the expression of hTERT correlates with telomerase activity (Hara et al., 2001; Kumaki et al., 2001). Thus, detection of the bTERT mRNA is considered a more reliable marker of the presence of cancer cells in clinical samples (Chen et al., 2011). In our study bTERT expression was detected in $97.5 \%$ (39/40) of 
NSCLC tumor specimens and in 75\% (24/32) of noncancerous specimens and it was significantly higher in cancerous tissues $\left(p=5.24 \times 10^{-4}\right)$. Our results are consistent with other authors (Hara et al., 2001; van den Berg et al., 2010). Fujita et al. suggested that bTERT mRNA expression may be useful for the diagnosis of NSCLC and may be an independent prognostic factor for patients with NSCLC. Nevertheless, in that study bTERT mRNA was detected by an in situ hybridization in 146 formalin fixed, paraffin embedded tissues. They found a significant correlation between bTERT mRNA expression, pathologic tumor status (pT), and the clinical stage, but similarly to our results, in their group no significant correlation between hTERT mRNA expression and age, gender, pathologic lymph node status $(\mathrm{pN})$, histology, or tumor differentiation was revealed (Fujita et al., 2003). Surprisingly, in our study a significant difference in hTERT expression between two types of histopathological pattern (adenocarcinoma and SCC) was detected $(p=0.01)$ (Table 2). A similar difference was not found in the other authors' studies. This observation needs to be verified in a much larger cohort of patients diagnosed with these two histological types of NSCLC. However, the percentages of samples with bTERT expression among non-cancerous tissues in our group are much higher than in other authors' studies (Hara et al., 2001; Hashim et al., 2011; van den Berg et al., 2010). This may result from the presence of epithelial cells in the samples of lung tissue. It is known that in normal adult tissues telomerase activity appears to correlate well with the differentiation stage of a cell as well as with its potential to act as a stem cell on appropriate stimulation. Telomerase expression correlates with self-renewal potential in many cell types including epithelial cells (Driscoll et al., 2000).

In our study, based on information about the patients' dates of death the 1-, 2-, and 5-year survival rates were calculated and then correlated with bTERT expression. No significant differences in bTERT expression in tumor tissues between deceased and living patients one, two, and five years after surgery were found (Table 2). Although numerous studies associate bTERT overexpression with poor prognosis (Fujita et al., 2003; Marchetti et al., 2002; Wang et al., 2002), other have failed to demonstrate any prognostic impact of this factor for NSCLC patients' survival rate (Kumaki et al., 2001; Lu et al., 2004). Marchetti et al. have shown that bTERT expression levels are strongly correlated with a reduced probability of survival in stage I NSCLC patients (Marchetti et al., 2002), while $\mathrm{Lu}$ and coworkers observed a lack of prognostic significance for bTERT mRNA expression in resected stage I NSCLC patients (Lu et al., 2004). Moreover, Metzger and coworkers have demonstrated a survival benefit for NSCLC patients with high bTERT mRNA expression (Metzger et al., 2009). The explanation of molecular processes resulting in such an effect remain to be discovered. Another problem is that the total cellular RNA was extracted from lung tissues which contain epithelial cells exhibiting telomerase expression; therefore, it is not possible to know whether telomerase activity is coming from the tumor cells in the sample. To overcome this limitation, a quantitative analysis of gene expression in microdissected tumor tissue would be required (Specht et al., 2001). However, this technique cannot be widely used in hospital practice because of high costs and lack of access to a highly specialized laboratory that applies molecular biology techniques.

Despite the unquestionable role of telomerase in the biology of immortalized cancer cells, its relationship with clinical parameters is not completely understood. Per- haps increasing data on observations linking molecular biology methods with clinical diagnostics, therapy monitoring procedures and survival rate analyses will create a sufficient base for further meta-analyses. Our study may serve as another observation in the discussion of the role of these parameters in NSCLC.

\section{CONCLUSION}

We have shown the association between bTERT mRNA expression and histological type of the cancer. Based on this, we concluded that $b T E R T$ mRNA detection by QRT-PCR can be used as a diagnostic marker in patients with NSCLC.

bTERT mRNA expression in NSCLC specimens does not correlate with survival rates and seems not to be a prognostic factor.

\section{Acknowledgements}

This study was supported by the grant from Medical University of Silesia (KNW-1-061/N/6/0).

\section{REFERENCES}

Albanell J, Lonardo F, Rusch V, Engelhardt M, Langenfeld J, Han W, Klimstra D, Venkatraman E, Moore MA, Dmitrovsky E (1997) High telomerase activity in primary lung cancers: association with increased cell proliferation rates and advanced pathologic stage. $J$ Natl Cancer Inst 89: 1609-1615

Armanios M, Blackburn EH (2012) The telomere syndromes. Nat Rev Genet 13: 693-704. doi: 10.1038/nrg3246

Chen C-H, Chen R-J (2011) Prevalence of telomerase activity in human cancer. J Farmos Med Assoc 110: 275-289

Dobija-Kubica K, Zalewska-Ziob M, Bruliński K, Rogoziński P, Wiczkowski A, Gawrychowska A, Gawrychowski J (2016) Telomerase activity in non-small cell lung cancer. Pol J Thorac Cardiovasc Surg 13: 15-20

Driscoll B, Buckley S, Chi Bui K, Anderson KD, Warburton D (2000) Telomerase in alveolar epithelial development and repair. Am J Physiol Lung Cell Mol Physiol 279: L1191-L1198

Ettinger DS, Akerley W, Bepler G, Blum MG, Chang A, Cheney RT, Chirieac LR, D'Amico TA, Demmy TL, Ganti AK, Govindan R, Grannis FW Jr, Jahan T, Jahanzeb M, Johnson DH, Kessinger A, Komaki R, Kong FM, Kris MG, Krug LM, Le QT, Lennes IT, Martins R, O’Malley J, Osarogiagbon RU, Otterson GA, Patel JD, Pisters KM, Reckamp K, Riely GJ, Rohren E, Simon GR, Swanson SJ, Wood DE, Yang SC (2010) Non-small cell lung cancer, version 6.2015. J Natl Compr Cancer Network 8: 740-801

Fujita Y, Fujikane T, Fujiuchi S, Nishigaki Y, Yamazaki Y, Nagase A, Shimizu T, Ohsaki Y, Kikuchi K (2003) The diagnostic and prognostic relevance of human telomerase reverse transcriptase mRNA expression detected in situ in patients with non-small cell lung carcinoma. Cancer 98: 1008-1013

Goldstraw P, Crowley J, Chansky K, Giroux DJ, Groome PA, Rami-Porta R, Postmus PE, Rusch V (2007) The IASLC Lung Cancer Staging Project: Proposals for the Revision of the TNM stage groupings in the forthcoming (seventh) edition of the TNM classification of malignant tumours. J Thorac Oncol 2: 706-714

Hara H, Yamashita K, Shinada J, Yoshimura H, Kameya T (2001) Clinicopathologic significance of telomerase activity and hTERT mRNA expression in non-small cell lung cancer. Lung Cancer 34: 219-226

Hashim M, Sayed M, Samy N, Elshazly S (2011) Prognostic significance of telomerase activity and some tumor markers in non-small cell lung cancer. Med Oncol 28: 322-330

Hiyama E, Hiyama K, Yokoyama T, Shay (2001) Immunohistochemical detection of telomerase (hTERT) protein in human cancer tissues and a subset of cells in normal tissues. Neoplasia 3: 17-26

Hiyama E, Hiyama K (2001) Clinical utility of telomerase in cancer. Oncogene 21: 643-649

Jafri MA Ansari SA, Alqahtani MH, Shay JW (2016) Roles of telomeres and telomerase in cancer, and advances in telomerase-targeted therapies. Genome Med 8: 69. doi: 10.1186/s13073-016-0324-x.

Kim NW (1997) Clinical implications of telomerase in cancer. Eur J Cancer 33: 781-786

Kumaki F, Kawai T, Hiroi S, Shinomiya N, Ozeki Y, Ferrans VJ, Torikata C (2001) Telomerase activity and expression of human telom- 
erase RNA component and human telomerase reverse transcriptase in lung carcinomas. Hum Pathol 32: 188-195

Livak KJ, Schmittgen TD (2001) Analysis of relative gene expression data using Real-Time Quantitative PCR and the $2^{-\triangle \Delta C T}$ method. Methods 25: 402-408

Lu C, Soria JC, Tang X, Xu XC, Wang L, Mao L, Lotan R, Kemp B, Bekele BN, Feng L, Hong WK, Khuri FR (2004) Prognostic factors in resected stage I non-small-cell lung cancer: a multivariate analysis of six molecular markers. J Clin Oncol 22: 4575-4583

Marchetti A, Bertacca G, Buttitta F, Chella A, Quattrocolo G, Angeletti CA, Bevilacqua G (1999) Telomerase activity as a prognostic indicator in stage I non-small cell lung cancer. Clin Cancer Res 5: 2077-2081

Marchetti A, Pellegrini C, Buttitta F, Falleni M, Romagnoli S, Felicioni L, Barassi F, Salvatore S, Chella A, Angeletti CA, Roncalli M, Coggi G, Bosari S (2002) Prediction of survival in stage I lung carcinoma patients by telomerase function evaluation. Lab Invest 82: 729-736

Metzger R, Vallbohmer D, Muller-Tidow C, Higashi H, Bollschweiler E, Warnecke-Eberz U, Brabender J, Baldus SE, Xi H, Berdel WE, Serve H, Hoelscher AH, Schneider PM (2009) Increased human telomerase reverse transcryptase mRNA expression but not telomerase activity is related to survival in curatively resected non-small cell lung cancer. Anticancer Res 29: 1157-1162

Mocellin S, Pooley KA, Nitti D (2013) Telomerase and the search for the end of cancer. Trends Mol Med 19: 125-33. doi: 10.1016/j.molmed.2012.11.006

Palm W, de Lange T (2008) How shelterin protects mammalian telomeres. Annu Rev Genet 42: 301-334. doi: 10.1146/annurev.genet.41.110306.130350
Parkin DM, Bray F, Ferlay J, Pisani P (2005) Global cancer statistics 2002. CA Cancer J Clin 55: 74-108

Radziszewska A, Kaczmarek-Borowska B, Gradalska-Lampart A, Filip AA (2015) Epidemiology, prevention and risk morbidity factors for lung cancer. Pol Med J 37: 113-118

Shay JW, Bacchetti S (1997) A survey of telomerase activity in human cancer. Eur J Cancer 33: 787-791

Shay JW, Wright WE (2000) Hayflick, his limit, and cellular ageing. Nat Rev Mol Cell Biol 1: 72-76. doi:10.1038/35036093

Shay JW, Wright WE (2005) Senescence and immortalization: role of telomeres and telomerase. Carcinogenesis 26: 867-874

Specht K, Richter T, Müller U, Walch A, Werner M, Höfle H (2001) Quantitative gene expression analysis in microdissected archival formalin-fixed and paraffin-embedded tumor tissue. Am J Pathol 158: 419-429. doi: 10.1016/S0002-9440(10)63985-5

Van den Berg RM, Brokx H, Vesin A, Field JK, Brambilla C, Meijer CJ, Sutedja GT, Heideman DA, Postmus PE, Smit EF, Snijders PJ (2010) Prognostic value of hTERT mRNA expression in surgical samples of lung cancer patients: the European Early Lung Cancer Project. Int J Oncol 37: 455-461

Wang L, Soria J-Ch, Kemp BL, Liu DD, Mao L, Khuri FR (2002) hTERT expression is a prognostic factor of survival in patients with stage I non-smal cell lung cancer. Clin Cancer Res 8: 2883-2889

Weinrich SL, Pruzan R, Ma L, Ouellette M, Tesmer VM, Holt SE, Bodnar AG, Lichtsteiner S, Kim NW, Trager JB, Taylor RD, Carlos R, Andrews WH, Wright WE, Shay JW, Harley CB, Morin GB (1997) Reconstitution of human telomerase with the template RNA component hTR and the catalytic protein subunit hTRT. Nat Genet 17: $498-502$ 